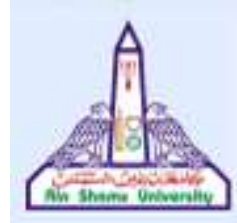

Ain Shams University

Faculty of Education

Curriculum \& Instruction Department

Using Reading Circles Strategy for Developing Preparatory

Students' Critical Reading Skills and Social Skills
A Paper presented
By
Mohamed Mahmoud Ibrahim Abdelrasoul
(A Teacher of English at the Ministry of Education,
Sohag Governorate) 


\section{Using Reading Circles Strategy for Developing Preparatory Students' critical Reading Skills and Social Skills.}

\section{Abstract:}

The present study aimed at developing the necessary critical reading skills and social skills for Egyptian EFL second year preparatory school students, through a proposed program based on using reading circles strategy. The study adopted the quasi-experimental pre-post test one study group design. The study sample consisted of 44 students from Sohag Experimental Preparatory School in Sohag Governorate. Who were trained to use the reading circles strategy. The program lasted for about 30 weeks during the academic year 2012/2013. Tools of the study included: A social skills questionnaire, a pre-/post critical reading skills test, reading circles roles sheets, and reflection sheets. The study results revealed that there were statistically significant differences at 0.01 level between the mean scores of the study group in the pre and post test in favor of the post administration. The main differences were clearly shown in the overall critical reading skills as well as in each sub critical reading skill. There were also statistically significant differences at 0.01 level between the mean scores of the study group in the pre and post-administrations of the social skills questionnaire in favor of the post-administration. .

The use of reading circles strategy increased students' critical reading skills and social skills. Students mentioned that they learned how to summarize topics in few sentences. They acquired the following skills: (1) looking up words in a dictionary, (2) differentiating between a fact and an opinion, (3) expecting, the topic of a passage or a story, (4) making 
connections between the stories they read and similar incidents they knew about; and (5) working in groups. Moreover, they enjoyed drawing pictures of the lessons and stories. They also acquired some social skills like respecting friends, listening to others and helping them..

Key Words: Reading Circles, Critical Reading Skills, Social Skills 


\section{Context of the problem}

Several studies have been implemented in Egypt to investigate students' reading skills such as El-Didi (2001), Abdelmoaty (2002) and Abouhadid (2002) emphasized that EFL reading comprehension skills are neglected in Egyptian classes. They also highlighted the need for adopting better teaching strategies to enhance EFL learner's reading skills. Similarly, Ibrahem (2007, p.5) mentioned that there was a low level of reading comprehension among students at the second year of preparatory governmental schools. She added that students are not proficient in reading, are poor readers and consequently are poor comprehenders. Furthermore, in Iran, Sharifian (2005) found that there is a significant correlation between the ability to determine fact and opinion, and the general reading comprehension skill. Critical reading skills require deep understanding. Also, Bedee (2010) added that teachers have begun to use literature circles within their classrooms, but some teachers are still apprehensive because they do not know whether they are as beneficial as the traditional reading instruction/discussion strategies that they are already using. Hence, more empirical studies are needed to investigate the effectiveness of reading/ literature circles in classrooms, and specially in EFL classrooms. The above mentioned studies pave the way to this study to be tried here in Egypt.

In the Egyptian context, there are some studies which investigated social skills such as Basta (2001) and Aboulaila (2002) who found that parents and educators maltreatment of children lead to their misbehaving and resistance. According to Salha $(2007$, p.4) Misbehaving is one side of 
the lack of social skills. Misbehaving of children who are maltreated can be seen at school when those school children are aggressive, refuse to abide by regulations, cause chaos, resist and refuse to cooperate with their mates. Basta (2011, p.15) mentioned that behavioral problems increase when students have weak ties with their teachers. This happens when students are not allowed to talk about themselves or express their opinions. Students also misbehave when they do not participate in discussions or ask personal questions. She confirms that when students are given opportunity to participate in and comment on topics being discussed in classrooms this lessens troubles, aggression and bad-behaving

It is really important to pay attention to preparatory students' social skills. Lacking proper social skills may lead to improper sequences on preparatory students.

Costley (2012) adds that parents' focus has turned from positive behavior skills and character building skills to content area instruction and test scores. He comments that society has changed drastically throughout history. Students twenty years ago behaved differently than the students of today. Students do not seem to be getting the same core, moral, and character values that were previously taught by the parents. Therefore it has been left up to the schools to fill in the gap. Costley also claims that parents do not care about their children's morals and values as they used to be twenty years ago

It can be inferred from the above mentioned studies that depriving students from reading skills can result in violence and crime as mentioned in the Reading at risk report. There is a demand to encourage Egyptian 
preparatory students to read and to use critical reading skills to be able to understand, comment, analyze and judge what they read. Students' social skills need attention to be paid to. Those skills need to be developed and improved. Akasha and Abdelmeguid (2012) see that even gifted students who excel their mates in subject matters are still in need of improving their social skills.

\section{Statement of the Problem}

The research problem can be summarized as follows:

The preparatory students are weak in using critical reading skills in reading English articles, stories or books and lack the proper social behavior in their communication.

\section{Questions of the study}

The study tried to answer the following questions:

1- What is the effect of using the reading circles on developing preparatory students' critical reading skills and social skills? To answer this main question, the following sub-questions were also answered:

2- What is the current situation concerning the reading skills and social skills of preparatory students?

3- What are the principles upon which a reading circles strategy-based program will be based for developing preparatory students' critical reading skills and social skills?

4- What is the framework of a reading circles strategy-based program in light of the previously mentioned principles? 
5- What is the effectiveness of the proposed program in developing preparatory students' critical reading skills and social skills?

\section{Hypotheses of the study}

The investigated hypotheses were as follow:

1- There are statistically significant differences between participants mean scores on the overall pre and post test on the critical reading skills in favor of the post test.

2- There are statistically significant differences between participants mean scores on the pre and post test on each critical reading sub-skill in favor of the post test.

3- There are statistically significant differences between the mean scores in the social behavior skills in favor of the post treatment.

4- There are statistically significant differences between the mean scores in each sub-social skill in favor of the post treatment

\section{Design of the study}

The present study made use of the quasi-experimental one group prepost test design. It aimed at investigating the effectiveness of the proposed program based on using reading circles in developing some critical reading skills and social skills of the study participants. Two classes (one for boys and one for girls) were selected at random in order to represent the study group. The students received the instruction through the proposed program. A pre-post test and questionnaire were administered to the participants. 


\section{Variables of the study}

In this present study there is one independent variable and two dependent ones. They are as follow:

1- The independent variable

It is a suggested training program based on reading circles strategy.

2- The dependent variables

a) developing some EFL critical reading skills.

b) developing social skills.

\section{Participants of this study:}

The expected number of participants was 57 students $(26 \mathrm{f}+31 \mathrm{~m})$. A total of 13 students were not included in the assessment of the program (as 6 students used to be absent most of the days of the academic year and 7 their guardians refused their participation in the program). The rest of students who attended were punctual and got their guardians' approvals to participate in this study $(n=44), 2 n d$ preparatory grade students in an experimental school in Sohag governorate called Sohag Experimental language school. The participants were selected randomly from the academic year 2012/2013. They were assigned into one group of boys and girls. The group consisted of 22 boys and 22 girls. The age of those students ranged from 13-14 years.

\section{Instruments of the study}

The present study utilized the following instruments:

1- A Critical reading skills test 
2- A Social skills Questionnaire

3- A Student's reflection log

\section{Duration of the proposed program}

The experiment lasted 30 weeks during the school year 2012 / 20103. It started on September $25^{\text {th }}, 2012$ and ended in April, 2013. The program was taught by the researcher himself in Sohag Experimental Language School. The researcher used to meet the students five days a week according to his timetable - Every unit took about four weeks to be taught. The time allocated for English was 90 minutes every day with total of 450 minutes per week. Every Thursday was dedicated to the program and students' presentations.

\section{Procedures}

\section{Instructional procedures}

To achieve the program objectives, the coming procedures were followed:

\section{A- Introduction:}

At the beginning of every unit, the researcher introduced the unit and its aims to the students. Units varied in sequence and time according to the school year variables, nature of units and students' readiness. For example unit one was introduced in two successive weeks and students kept practicing the cooperative and administrative roles throughout the classroom English activities. They were integrated with the regular teaching process as well as the program. Unit two was introduced after 
that also in two successive weeks. The members of groups were met separately according to their roles to assure that they understood the roles thoroughly and could implement them accurately. The meetings were held during the break time. This unit was also integrated with the regular teaching and the cooperative roles. It was mainly applied to the novel of Charles Dickens ' David Copperfield" (See sample of the chapters, Appendix E). Units three and four of the program were dedicated to the introduction and practice of the social skills. Unit three consisted of 12 sessions and unit four consisted of seven sessions. The sessions were introduced in the form of a daily $15: 20$ minute session. Every day a new concept was introduced and modeled by the researcher. Students then practiced it. After that they performed a task related to this skill either at school or at home. Unit five of the program contains the reading passages used in the program. They consist of 43 different passages. The passages which are selected from the text books are studied by all students. (no =27). There are other passages for groups to select from $(\mathrm{no}=16)$

B- The researcher stated the objectives of every session.

\section{C- Warm up}

The researcher made appropriate warm up using various techniques such as reviewing roles, definitions and other techniques. Warm up activities were used in a pre-reading stage in this program. 


\section{D- Presentation}

The presentation steps of each session followed the following pattern:

1. During the first month of program application students were introduced to and practiced the six social roles for two weeks.

2. Administrative roles were assigned to students and were divided into seven heterogeneous groups. As classrooms were separated according to gender, there were four boy groups and three girl groups.

3. From the third week of program's implementation, the reading roles were introduced and practiced for two weeks.

4. From the beginning of the second month, groups were established and started performing the tasks. Every group included 12 roles, six social roles and six reading roles. The social roles included a group leader, a spokesperson, a time keeper, a store keeper, a checker, and a recorder. The members of each group work and interact with each other in most of the activities.

5. The reading roles for the group members included DD (discussion Director), WW (word wizard), C A (creative artist), S C (story connector), S S (story summarizer) and C (Checker).

6. Every group began to interact with pre-reading activities to recall their background knowledge and learn about the objectives of the lesson.

7. Then, the students were asked to carry out the procedures during reading stage which was in the form of silent reading/group reading 
of certain passages and doing certain tasks related to the activities of the lesson.

8. After reading students present their findings as a team according to their assigned roles. (See Reading Circles Role Sheet in the Tool Box Section Appendix E).This stage was related strongly to the previous activities.

9. After the students evaluated their own abilities, they began to make a sort of self-assessment through engaging in reflection worksheets. Reflection worksheets were very important to both researcher and students as they clarified and exposed the difficulties the researcher and the students faced during the sessions. See Table

(8) for program teaching's plan.

10.Each group kept a porto-folio which contained a copy of the group performance and work.

11.Each member of the groups kept a copy of the Respect Building note book to register the progress of their social skills.

12.Weekly meetings were held with the group leaders to distribute the selected passages to be prepared for Thursday presentations. In the following lines the roles of the teacher and students are presented.

\section{Instruments of the study}

The present study utilized the following instruments:

1. Pre-/Post critical reading skills test was used to measure students' skill to differentiate fact from opinion, anticipation, word knowledge, reference, summarization, and relating new knowledge to previous experience.

\section{3}


2. Social skills questionnaire to measure students' awareness and following. Validity and reliability were obtained.

3. A Student's reflection log

\section{Results}

1. There are statistically significant differences between the mean scores between the pre test and post test on the reading skills favoring post test at .01 level.

2. There are statistically significant differences between the mean scores in the social behavior skills favoring post treatment at .01 level.

3. The qualitative phase of the study showed how the program started and how students' skills improved over time. It also showed how important support and collaboration is needed from every stakeholder of the school community, teachers, school administration, parents and students themselves.

\section{Findings}

\section{The findings of the study can be summed up in the following:}

First: The use of reading circle strategy increases students' critical reading skills. This can take place through developing their abilities to differentiate between fact and opinion, learning and identifying new words, anticipate what a passage is going to be about and how it is going to finish, refer to information in the passage, summarize, and connect with previous knowledge.

Second: Reading circles strategy helps students acquire self-monitoring and problem solving skills through the use of student partnerships 
for practice with each student participating in reading and tackling passages from different perspectives.

Third: Reading circles strategy could be used to improve and foster active listening skills in students.

Fourth: Reading circles strategy was an opportunity for building students' cooperation and dedication to their groups.

Fifth: reading circles strategy could be used to create situations for students to show respect for themselves, the others and the environment

\section{Conclusions}

Based on the findings of the present study, the following conclusions could be stated:

1. It seems evident that using the reading circles strategy improves students' performance in critical reading skills (Differentiating between fact and opinion, anticipation, word knowledge, reference, summarization, and making connections between previous experience and new learnt knowledge.

2. Raising students' awareness of critical reading skills enhances their EFL Reading comprehension.

3. Creating a place in the Curriculum for reflection is very important as reflection helps promote self-assessment.

4. The present study showed that reading circles was an environment for improving students' social skills. 
5. The present study showed that students' positive behavior can be improved if it is given enough attention in classroom environment and activities and negative behavior can be decreased as well.

6. The present study showed the role of alternative assessment through the use of different handouts, skill evaluation matrices, worksheets, handouts response pages and forms of reflection.

7. There is an indication that when the learning process is centered on the students (student centered classroom) and the teacher's role is minimized, students are urged to think for themselves, take decisions, evaluate and judge without relying on their teacher's authority figure to take decisions for them. Thus, students centered classroom boosted their critical thinking skills.

8. It is important to set a purpose for reading. Readers trained in setting a purpose increase their reading comprehension skills.

9. Teachers should encourage students use words in multiple as this enhances word learning. Students should gather synonyms, antonyms, and homonyms, as well as words that present specific sounds and categories.

10. Students should be taught strategies to summarize reading texts.

11.Students should be encouraged to take notes to summarize.

12. Students showed their skills to invent and narrate similar stories to the ones they read in the role of the Connector when they found no connections so they should be encouraged to narrate their own stories. 


\section{Recommendations:}

In light of the results obtained in the present study, a number of recommendations could be helpful in the methodology of teaching English as a foreign language (EFL).These recommendations are as follow:

- Students should be given a safe and unthreatening learning environment which enables them to read independently and critically in English.

- Students should be encouraged to join reading circles in the experimental governmental preparatory schools to enhance their critical reading skills and social skills.

- Students' social behavior should be given due attention in the Egyptian schools.

- Teachers should assign out of class activities as well as in class activities to help students read more often using critical reading skills.

- Teachers should model critical reading strategies and social skills strategies with students.

- Schools should supply libraries with English books and stories.

- School leaders should encourage critical reading skills activities and inaugurating book clubs at schools.

- Curriculum developers are invited to enrich text books with activities which enhance students' critical reading and social skills and how to implement them

- Teacher's Guide should contain a checklist of the necessary EFL Critical Reading Skills and Social Skills and guidelines for hands on activities to foster them. 
- MOE should supply English curriculum with books and stories in all preparatory grades not only with preparatory three.

- Ministry of Education should encourage preparatory teachers implement cooperative learning, reading circles and social skills.

- Supervisors should encourage teachers to pay attention to students' social skills and critical reading skills.

\section{Suggestions for further studies:}

Replication of this study with modification is recommended. While it was the purpose of the study to investigate the effectiveness of using reading circles in enhancing preparatory two students' critical reading skills and social skills.

1) Further research is needed to develop other language skills (listening, speaking and writing through literature circles

2) Further research is needed with other student populations at different levels of education and in different locations of Egypt with the purpose of investigating the effectiveness of making use of reading circles strategy in developing their critical reading skills and social skills.

3) Other studies are needed to investigate the effectiveness of applying similar program over a longer period of time on students. 


\section{References}

Abdelmoaty, R. A. (2002). The effectiveness of using first year secondary students'

questions in developing their critical reading skills in light of schema theory.

Unpublished M. A. Thesis. Women's College, Ain Shams University.

Abou-hadid, A. A. ( 2002). The effectiveness of the cognitive and metacognitive

strategies on developing secondary school students' receptive skills.

Unpublished Ph.D. Dissertation. Women's College, Ain Shams University.

Aboulaila, B. A. (2002). Parents' treatment and its relation with behavioral disorders

as perceived by sons at preparatory stage in Ghaza Distrect. Unpublished

M. A. Faculty of Education, the Islamic University.

Akasha, M. F. and Abdelmugid, A.M.( 20012). Developing social skills of gifted

children with scholar behavioral problems. Arabic Magazine for Talent

Development, Talent Development Center.(4) p.p.116-147

Amer, W. S. T. (2009). The effect of using jigsaw II method on developing 
p reparatory one students' reading skills in English. Unpublished Master

Thesis. Menoufeya University.

Basta, F. A. ( 2001).The resistant child psychology. Unpublished M. A. thesis.

Faculty of Arts, El-Minya University.

(2011). The effectiveness of a counseling program of

behavior

modification of stubborn child. Unpublished Ph. D dissertation.

Faculty of

Arts, Sohag University.

Bedee, S. (2010, June 13). The Impact of Literature Circles on Reading

Motivation

and Comprehension for Students in a Second Grade

Classroom. (Electronic

M. A. Thesis). Bowling Green State University. Retrieved from

https://etd.ohiolink.edu

Costley, K. C.(2012). Character education: A growing need in American schools,

College of Education Graduate Student, Arkansas tech University.

El-Didi, N. A.( 2001). A proposal model for developing metacognitive problem- solving

reading strategies of secondary stage EFL teachers and students. Unpublished 
Ph.D. Dissertation. Faculty of Education, Ain Shams University. Ghahraki, S. \& Sharifian, F. (2005). The relationship between overall reading comprehension and determination of fact / opinion in L2. The Reading

Matrix. Vol.5, No.1, April 2005.

Ibrahem, S. A. M. (2007). A Training program in learning metacognitive strategies in

English to improve reading comprehension for low-achievers in preparatory

schools. Unpublished M.A. Thesis. Ain Shams University.

(NASBE) National Association of State Boards of Education (2006).

Reading at risk

report. ISBN 1-58434-064-9.

Salha, S. M. ( 2007). Behavioral troubles with blind children. M. A. thesis. Faculty of

Education, Damascus University. 